\title{
METHODOLOGICAL CREATIVITY IN PEDAGOGICAL RESEARCH - GLOBAL CHALLENGE
}

\author{
Snježana Dubovicki \\ Ph.D., Assistant Professor \\ Faculty of Education, Josip Juraj Strossmayer University of Osijek (Croatia)
}

\begin{abstract}
Most pedagogical issues cannot be explored or explained in the example of numerous indicators and mathematical analyzes. This does not mean that statistical indicators do not have to be present in pedagogical research, but it is emphasized that without any qualitative indicators not a single pedagogical phenomenon could be fully explored. This topic raised another important issue - the issue of publishing works in which mostly qualitative methodologies have been used in highly indexed journals. Such works by scientists (reviewers) are often classified as "works of the second order" because they do not show "higher" level of statistics. In addition, such works often do not pass the first step, which is a preliminary review that mainly refers to a methodological analysis. For these reasons, it is much easier to publish a paper using rather quantitative than qualitative methodology. Numerous researchers have already been alerted about this situation, and now it reached its peak.

We will come across a special report by scientists and reviewers if we use the futurology methods of research in the methodological part of the paper. This is, according to some, another step below the "evaluation" of those who do not even know the futurology research methods. As a counterpart to such an understanding and to the research corpus, there is a "third part". In addition to the quantitative and qualitative methodology we have a mixed methodology that seeks to alleviate the positivist approach in pedagogical research.

That opens some space for reflection on the new approach (in addition to the existing ones) in the methodology that would give a new framework for pedagogical phenomena. Can the choice of methodology be less restrictive for researchers? Is a high level of precision and the ability to check the results obtained, and thus greater relevance than the actual changes in practice? Can methodology be "creative"? Those are the questions that need answering.

The paper aims at raising awareness of the importance of a qualitative approach in the research of pedagogical problems and at offering ideas that can contribute to changes in the creation of a new methodological framework that certainly represents a new global challenge.
\end{abstract}

Keywords: Creativity methodological approach, mixed methodology, pedagogical research, qualitative methodology.

\section{Introduction}

The paper seeks to emphasize the need for equal representation of qualitative and quantitative research methods in research of pedagogical phenomena, since the exclusivity of one would distort the holistic approach. In an attempt to emphasize the situation "on the field" an analysis of graduate theses of the students of the Teacher Education (Faculty of Education, University in Osijek, Croatia), was conducted (Dubovicki, Mlinarević \& Velki, 2018) which showed that $60.6 \%$ of students in their graduation theses used survey as the only research instrument within the frame of the positivist paradigm. If we consider the fact that the most significant scientific area comes from social sciences (36.47\%), and within them from the field of pedagogy $(46.55 \%)$, we will notice an inequality of other scientific paradigms, and in particular the lack of other research methods that go hand in hand with qualitatively methodology. Sometimes we try to justify ourselves to our colleagues, saying that we, as mentors to students (graduates and/or Ph.D. students) used qualitative methods in our research. Nordstrom \& Happel-Parkins (2016) also warned about that state, referring to it as the methodological drag. 
"When we explain and defend qualitative research to, for example, skeptical colleagues, we must perform authoritatively and definitively. We must have the "Truth" about qualitative research even though we know there are multiple, contingent, and partial truths about qualitative research. We do this to justify and validate qualitative research to other faculty members and administrators so that our students' research can, in turn, be validated."

(Nordstrom \& Happel-Parkins, 2016, 151)

The so-called methodological resistance should not be a dogmatic term that seeks to reduce the presence of qualitative research methods, it should represent a strategy that seeks to open up multiple and contingent ways of understanding the qualitative methodology for all those who use the qualitative methodology in their future research. With qualitative data, we can reach the deepest human experience (Mitchell \& Clark, 2018) and they are thus extremely important in pedagogy.

\section{Problems of publishing pedagogical papers that used qualitative approaches}

Papers that used only qualitative methodology are often exposed to a greater number of criticism (mostly non-public) by scientists and reviewers who often reduce the value of papers written in such a way. By deciding to use qualitative research, you have already "cut down the chance" to have your work published in well-known and highly-indexed journals. Such papers often do not even pass the first step, which is a preliminary review that mainly refers to methodological analysis (Dubovicki, 2017). Suzić (2017) also points out that one of the most important conditions for publishing papers in highly indexed journals is, actually, the use of quantitative methodology (especially in the Balkans). Twining, Heller, Nussbaum \& Tsai (2017) emphasize the fact that qualitative research (due to ontological and epistemological viewpoints) does not take into account the sample representability for the whole population and for these reasons we cannot expect to be able to generalize the obtained data, as is the case with quantitative research. This can also undermine the categorization of work. Wishing for their papers to be approved and published (which is essential for collecting points for advancement at professional level), numerous pedagogues decide to use quantitative methodology and positivist paradigm in their research. Bognar (2012) warns us that such an attempt to apply the methodology of natural sciences to social sciences, alongside the aspiration to mathematize pedagogical phenomena, could lead to the complete separation of pedagogical theory from practice. The introduction of numerical methods in social sciences that are associated with rationalism (17th century) and positivism also contributed to this state. We can say that the new epistemology started, hand to hand, with the constitution of certain social sciences, especially pedagogy. Numerous researchers (Soltis, 1984; Bognar, 2012; Avenier \& Thomas, 2015; Dubovicki, 2017; Twining, Heller, Nussbaum \& Tsai, 2017; Mitchell \& Clark, 2018) warned about this situation, which reached his peak a few years ago (especially in Croatia). Serikov (2016) points out that it would be desirable to use Volodar Viktorovich Kraevsky's ideas in the research of pedagogic phenomena. Pedagogical methodology should offer a creative approach towards research, via the creative activity of researchers.

"The purpose of methodology is to substantiate the means of constructing pedagogical theory as a cognitive construction that supports a trinity of functions: explanations, designs, and forecasts of the functioning and genesis of pedagogical reality. The aggregate of activities that substantiate the means of perceiving pedagogical reality comprises methodological activities in pedagogy. "

Serikov (2016, 527)

This state of affairs is less alarming if we only take into consideration the publication of the papers (and its methodology), however, if we add, to the mentioned above, the situations in which the success of the projects are evaluated (in the end) according to the number of published papers and/or the themes of doctoral dissertation filed via a form that requires solely positivist paradigm (Bognar, 2012), then we should wonder about the direction in which the pedagogical research is heading. Suzić (2017) highlighted a few useful tips, in order to warn about the problems of publishing pedagogical papers connected to qualitative research.

"Qualitative researches derive meaning from multiple sources, but also look for an account of the phenomenon by examining and describing the history of it, and by presenting the current status of the subject matter in relation to the author's course of action...Qualitative research is only useful if the background information is provided concisely and straightforwardly."

(Suzić, 2017, 136) 
Futurology methods of research represent an additional challenge for researchers. In addition to being insufficiently represented in all areas and fields of science, insufficiently known and inadequately applied in research of pedagogical terms, most of them still belong to the qualitative paradigm (Dubovicki, 2017). An interesting fact that also points to this is the lack of reviewers from the area of futurology. This paper also raises the question about the "expertise" of the reviewers for papers which used futurology research methods. Suzić (2017) also writes about the similar situations when it comes to the reviewing of the papers which demonstrate higher statistical and methodological procedures. It is desirable (and necessary) to carefully select the reviewers because it is common practice that reviewers are often chosen "from home" and for more or less known reasons. Another problem with the selection of reviewers is related to papers written in the languages of minorities, so such papers (written in the Balkan languages) are often a priori "condemned" to reviewers from those areas who may not be the best and/or most competent, but there is no other choice. Keeping all this in mind, we can also think about the right choice of categorization of individual papers published in such magazines (Hannes, Heyvaert, Slegers, Vandenbrande \& Nuland, 2015). On the other hand, similar problems appear less in the reviews of papers that primarily use statistical indicators.

\section{Discussion}

It should be emphasized that a paper does not a priori use qualitative methodology (nor quantitative) since the methodology of each work is determined regarding the set hypothesis/research question. Unfortunately, that is not always the case. Mentors often give their graduates already finished instruments (most often surveys) which they then use in their research so that the applicants do not have to go back to pilot studies (check reliability) on some newly-built instruments (Dubovicki, Mlinarević $\&$ Velki, 2018). Also, the value of some papers should not be determined by the type of methodology and choice of research instruments.

Contributions to this topic are also provided by instructions from certain journals or conference organizing committees (in the form of templates) which require participants to respect the default "mold", often written in the form of: Introduction, Methods, Hypothesis, Research Results and Interpretation, Discussion, Conclusion and References. Some researchers see a solution in the use of mixed methodology, which is becoming more and more popular. The majority of today's researchers (Burke, Onwuegbuzie \& Turner 2007) point out that methodology is still divided into: qualitative, quantitative, and research using mixed methodology. Burke, Onwuegbuzie \& Turner (2007) present a brief history of mixed methods and point out that it is necessary to respond to the issues that have emerged recently due to the increased number of researchers who conduct their research using mixed methodology. Kumsa, Chambon, Chung Yan \& Maiter (2014) also emphasize the importance of methodological validity that we need to pay attention to in the participatory research. In our paper, we examine the messy processes in the preliminary phase of their research project and the invaluable insights we took into developing a creative methodology. Mason (2006) emphasizes the importance of 'qualitative thinking' as a useful starting point for mixing methods, but says that it is ultimately more useful to think in terms of multi-dimensional research strategies that transcend or even subvert the so-called qualitative-quantitative divide. Gorard and Taylor (2004) emphasize the importance of data obtained by combining the method, pointing out that the lack of one research method can be compensated by complementing the other by contributing to the credibility of the obtained results. Soltis (1984) writes that about the importance of exploring and studying the pedagogical phenomena using different scientific paradigms, but also the openness of the researcher towards personal rational assessment regarding the set research claims. When it comes to the research of pedagogical issues, Matijević \& Topolovčan (2017) in advocate the synthesis of qualitative and quantitative approaches that can be formed on the basis of: additive interconnection, triangulation and transformation with the help of transforming qualitative data into quantitative and vice versa. The quality of the collected data depends on the appropriateness of the methods used, the quality of the individual data collection instruments and the process of utilizing those instruments. Evidence should be collected from multiple sources to enable triangulation (Baškarada, 2014).

Braun \& Clarke (2006) note that the criteria for the evaluation of qualitative and quantitative research should be equally rigorous. There is a question of assessing the quality of qualitative research and of having a set of criteria that are suitable for all qualitative approaches (Reicher, 2000; Braun \& Clarke, 2006; Hammersley, 2007). Some researchers (Spencer, Ritchie, Lewis \& Dillon, 2003; Hannes et al., 2015) objected to such generic guidelines precisely because of the specificity of particular sciences and specific challenges within which research is being conducted. It should be kept in mind that no research approach should be exclusive, and that no research technique should be idealized. Although the paper is focused on the affirmation of qualitative research techniques in pedagogical research (and even representation in relation to quantitative ones), it is important to warn researchers of some of the 
shortcomings. Twining et al. (2017) state that qualitative research often collects very much data, and researchers therefore need to be extremely skilled in the interpretation of the said data. In addition, data gathering should focus on answering the research questions. That process is often difficult since the researcher simultaneously collects and analyses the data, so it is important to avoid being superficial in doing so.

\section{Conclusion}

In order to influence the changes of the current situation, and improve the even representation of qualitative and quantitative methods in pedagogical research, it is certainly necessary to revise the existing patterns for the selection of topics for graduate, master and doctoral theses, in which the candidates should most often opt for quantitative methodology. In addition, it is necessary to approach the new editorial philosophy and politics of pedagogical journals that need to be open to different approaches and scientific paradigms (Bognar, 2012).

The global challenge in the development of pedagogical methodology is the correlation of research with practice and the influence of changing condition, emphasizing the theoretical foundation and holistic approach of the researched issue. A new approach to methodology should at least be creative - directed at the freedom of the researcher and adaptable to the "field" situation. These changes should also be present during the education of students within the methodological courses at the faculties.

\section{References}

Avenier, M.-J. \& Thomas, C. (2015). Finding one's way around various methods and guidelines for doing rigorous qualitative research: A comparison of four epistemological frameworks. Systèmes d'Information et Management, 20(1), 61-98.

Baškarada, S. (2014). Qualitative Case Study Guidelines. The Qualitative Report, 19, 1-18.

Bognar, L. (2012). Pedagogija kao odraz postojećeg ili kreiranje mogućeg. U: (Ed. N. Hrvatić, A. Klapan, Anita) Pedagogija i kultura, 111-121. Zagreb: Hrvatsko pedagogijsko društvo

Braun, V. \& Clarke, V. (2006). Using thematic analysis in psychology. Qualitative Research in Psychology, 3(2), 77-101. https://doi.org/10.1191/1478088706qp063oa

Burke R. J., Onwuegbuzie, A. J., Turner, L. A. (2007). Toward a Definition of Mixed Methods Research. Journal of Mixed Methods Research, 112-133. https://doi.org/10.1177\%2F1558689806298224

Dubovicki. S. (2017). Futurološke metode istraživanja. U: (Ed. S. Opić, B. Bognar i S. Ratković) Novi pristupi metodologiji istraživanja odgoja, 203-221. Zagreb: Učiteljski fakultet Sveučilišta u Zagrebu

Dubovicki, S., Mlinarević, V. \& Velki, T. (2018). Istraživački pristupi i metodološki okviri u istraživanjima budućih učitelja. Nova prisutnost, 16(3), 595-611

Gorard, S. \& Taylor, C. (2004). Combining Methods in Educational and Social Research. Maidenhead: Open University Press.

Hammersley, M. (2007). The issue of quality in qualitative research. International Journal of Research \& Method in Education, 30(3), 287-305.

Hannes, K., Heyvaert, M., Slegers, K., Vandenbrande, S., \& Nuland, M. V. (2015). Exploring the Potential for a Consolidated Standard for Reporting Guidelines for Qualitative Research an Argument Delphi Approach. International Journal of Qualitative Methods, 14(4), 1-16. DOI: $10.1177 / 1609406915611528$

Kumsa, M. K., Chambon, A., Chung Yan, M., Maiter, S. (2014). Catching the shimmers of the social: from the limits of reflexivity to methodological creativity. Qualitative Research, 15(4), 419-436. https://doi.org/10.1177/1468794114538897

Mason, J. (2006). Mixing methods in a qualitatively driven way. Qualitative Research, 6(1), 9-25. https://doi.org/10.1177\%2F1468794106058866

Matijević, M. \& Topolovčan, T. (2017). Multimedijska didaktika. Zagreb: Školska knjiga

Mitchell, K. M. \& Clark, A. M. (2018). Five Steps to Writing More Engaging Qualitative Research. International Journal of Qualitative Methods, 17(1), 1-3. https://doi.org/10.1177/1609406918757613

Nordstrom, S. N. \& Happel-Parkins, A. (2016). Methodological Drag: Subversive Performances of Qualitative Methodologist and Pedagogical Practices. Qualitative Inquiry, 22(2), 149-153. DOI: $10.1177 / 1077800415620221$ 
Reicher, S. (2000). Against methodolatry: some comments on Elliott, Fischer, and Rennie. British Journal of Clinical Psychology, 39, 1-6.

Serikov, V. V. (2016). Will Pedagogy Become a Science? Reflections on the Methodology of V.V. Kraevsky. Russian Education \& Society, 58(7-8), 521-537.

Soltis, J. F. (1984). On the Nature of Educational Research. Educational Researcher, 13(10), 5-10. https://doi.org/10.3102\%2F0013189X013010005

Spencer, L., Ritchie, J., Lewis, J. \& Dillon, L. (2003). Quality in Qualitative Evaluation: A framework for assessing research evidence. London: The Cabinet Office.

Suzić, N. (2017). How to publish Work in indexed scientific Journals - an overview. Research in Pedagogy, 7(1), 134-144. DOI:10.17810/2015.55

Twining, P., Heller, R. S., Nussbaum, M. \& Tsai C. C. (2017). Some guidance on conducting and reporting qualitative studies. Computers \& Education, 108(1), 1-9. https://doi.org/10.1016/j.compedu.2016.12.002 